\title{
Representações Sociais do Cuidado de Enfermagem em Saúde Mental na Atenção Básica
}

\author{
Social Representations of Nursing Care in Mental Health \\ in Primary Care
}

\author{
Edirlei Machado dos Santos' • Claudinei José Gomes Campos ${ }^{2}$ Helca Franciolli Teixeira Reis ${ }^{3}$ \\ Wanderley Matos Reis Júnior ${ }^{4} \bullet$ José Andrade Louzado ${ }^{5} \bullet$ Geslaney Reis da Silva $^{6}$
}

\section{RESUMO}

Esta pesquisa teve como objetivos analisar as ferramentas utilizadas por enfermeiras para o desenvolvimento do cuidado em saúde mental na Estratégia Saúde da Família e as limitações para a sua produção. Trata-se de uma pesquisa qualitativa do tipo estudo de caso. Os dados foram coletados por meio de entrevistas semiestruturadas e analisados a partir da Análise de Conteúdo Temática, a partir da Teoria das Representações Sociais. Foram depreendidas duas categorias: ferramentas utilizadas para a produção do cuidado em saúde mental e as limitações para a sua efetivação. As participantes da pesquisa ancoraram suas representações sociais em elementos que retrataram as possibilidades/limitações para o cuidado em saúde mental, principalmente, relacionadas ao usuário com transtorno mental. Destarte, as participantes da pesquisa reconheceram o encaminhamento/medicalização, o acolhimento/vínculo/escuta como possibilidades para produção do cuidado em saúde mental e apontaram as deficiências nos processos formativos e o medo como limitadores para a produção deste cuidado.

Palavras-chave: Serviços de Saúde Mental; Programa Saúde da Família; Pesquisa Qualitativa; Enfermagem.

\begin{abstract}
This research aimed to analyze the tools used by nurses for the development of mental health care in the Family Health Strategy and the limitations to their production. This is a qualitative case-study research. The data were collected through semi-structured interviews and analyzed from the Thematic ContentAnalysis, based on the Social Representations Theory. Two categories emerged: tools used for the production of mental health care and the limitations to its effectiveness. The research participants anchored their social representations in elements that portrayed the possibilities / limitations for mental health care, mainly related to the user with mental disorder.Thus, the research participants acknowledged referral / medicalization, welcoming / bonding / listening as possibilities for the production of mental health care, and pointed out deficiencies in the formative processes and fear as limiters for the production of this care.
\end{abstract}

Keywords: Mental Health Services; Family Health Program; Qualitative research; Nursing.

'Doutor em Enfermagem. Programa de Pós-Graduação em Enfermagem, Universidade Federal de Mato Grosso do Sul (UFMS), Campus de Três Lagoas (CPTL). edirlei.machado@ufms.br

2Doutor em Ciências Médicas. Programa de Pós-Graduação em Enfermagem, Universidade Estadual de Campinas (UNICAMP)

${ }^{3}$ Doutoranda em Enfermagem e Saúde, Universidade Federal da Bahia (UFBA), Instituto Multidisciplinar em Saúde (IMS)

${ }^{4}$ Doutorando em Epidemiologia. Universidade Estadual do Sudoeste da Bahia (UESB)

${ }^{5}$ Doutorando em Epidemiologia. Universidade Federal da Bahia (UFBA), Instituto Multidisciplinar em Saúde (IMS)

${ }^{6}$ Mestre em Enfermagem e Saúde. UNIMED Sudoeste 


\section{INTRODUÇÃO}

A inserção de ações de saúde mental nos serviços da atenção básica tem sido estimulada pela Organização Mundial da Saúde desde a década de 1990, uma vez que o aspecto emocional também deve ser considerado no processo saúde-doença das pessoas. Ressaltamos que a introdução de ações de saúde mental na atenção básica não deveria ser vista como mais uma tarefa ou como nova carga de trabalho, mas, como uma possibilidade de efetividade da integralidade na produção do cuidado em saúde ${ }^{(1)}$.

Ademais, as equipes de atenção básica, em especial as equipes de saúde da família, constituem-se num recurso estratégico para o enfrentamento de importantes problemas de saúde mental, para exemplificar, os transtornos mentais comuns, o uso abusivo de álcool, e de drogas e outras formas de sofrimento psíquico controlado que não exigem atenção psicossocial especializada ${ }^{(2)}$.

A temática saúde mental, em particular, no contexto dos serviços da atenção básica tornou-se tão importante que tem sido uma preocupação não só do governo e pesquisadores do Brasil, como também, de outros países. Num estudo em que os autores analisaram os problemas de saúde mental na atenção básica no Reino Unido, observaram deficiências na prática clínica e a necessidade de formação em saúde mental para os profissionais que atuam neste cenário, desenvolvendo ações de saúde mental ${ }^{(3)}$.

Noutra pesquisa os autores tomaram como objeto de estudo as políticas de saúde mental nas equipes de trabalho da atenção básica na Inglaterra e identificaram uma falta de clareza na política de saúde mental do país, sendo este um dos fatores que tem contribuído para as dificuldades encontradas pelos profissionais em atuarem em saúde mental(4).

As afirmações anteriores evidenciam a relevância da atenção básica como importante equipamento de atenção em saúde mental. Na quase totalidade dos municípios brasileiros, o modelo de atenção à saúde adotado, tem sido a Estratégia Saúde da Família. Destarte, conhecer de que forma os enfermeiros destas equipes representam às possibilidades e limitações para a produção do cuidado em saúde mental contribuirá para descontruir práticas e programar novas estratégias de cuidado em saúde.

Como referencial teórico, empregamos a Teoria das Representações Sociais que envolvem dois universos de pensamento: os universos consensuais e os reificados, correspondendo à formação das "teorias" do senso comum $^{5}$ e aqueles identificados com o conhecimento científico ${ }^{(5)}$, respectivamente.A formação das representações sociais se dá a partir de vários elementos, sendo utilizados na analise dos dados desta pesquisa os processos sociocognitivos de objetivação e ancoragem. A objetivação une a ideia de não familiaridade com a de realidade, tornando-se a verdadeira essência da realidade ${ }^{(6)}$. A an- coragem é um processo que transforma algo estranho e perturbador, que nos intriga, em nosso sistema particular de categorias e o compara com um paradigma de uma categoria que nós pensamos ser apropriada ${ }^{(6)}$.

Portanto, a investigação das Representações Sociais sobre as ferramentas e suas limitações para a produção do cuidado em saúde mental na atenção básica, na percepção de enfermeiros da Estratégia Saúde da Família, remete-nos a um conhecimento particular do grupo estudado, elaborado a partir de seu conhecimento científico e suas experiências de vida num contexto sociocultural determinado.

A presente pesquisa teve como objetivos: analisar as ferramentas utilizadas por enfermeiros para o desenvolvimento do cuidado em saúde mental e as limitações para a produção do cuidado em saúde mental na Estratégia Saúde da Família.

\section{MÉTODO}

Trata-se de uma pesquisa de abordagem qualitativa do tipo descritiva e exploratória em que se empregou o referencial metodológico do estudo de caso.

O método de estudo de caso consiste numa investigação empírica que analisa um fenômeno contemporâneo em profundidade e em seu contexto de vida real, especialmente quando os limites entre o fenômeno e o contexto não estão claramente evidentes ${ }^{(7)}$. Na presente pesquisa o caso foi composto por enfermeiras que atuavam em equipes de saúde da família no município de Vitória da Conquista, localizado na região sudoeste do estado da Bahia.

Os dados foram coletados após a aprovação do projeto de pesquisa pelo Comitê de Ética em Pesquisa da Fundação Municipal de Educação e Cultura de Santa Fé do Sul-SP por meio do Parecer de n. ${ }^{\circ}$ II 8 em 29/I I/20 II. A coleta dos dados foi feita no período compreendido entre fevereiro e abril de 2013, por meio de entrevistas semiestruturadas, sendo estas gravadas e tendo uma duração média de 20 minutos. Para tanto, elaboramos um roteiro composto de duas partes, a primeira formada por questões referentes ao perfil sociodemográfico das participantes do estudo e a segunda com a seguinte questão norteadora "Para você quais seriam as possibilidades/instrumentos e limitações para o desenvolvimento do cuidado em saúde mental na Estratégia de Saúde da Família?". Participaram do estudo 19 enfermeiras, sendo respeitados os critérios de inclusão: atuar em Estratégia Saúde da Família da zona urbana há no mínimo três meses e estar em exercício profissional no período de coleta de dados.

Previamente ao início da coleta de dados, realizamos um estudo de caso-piloto, com dois enfermeiros que não participaram da amostra final do estudo, cuja propos- 
ta foi a de nos auxiliar a refinar os planos de coleta de dados em relação ao conteúdo dos dados e aos procedimentos a serem seguidos. Após a coleta dos dados do caso-piloto realizamos a validação interna, sendo a validação externa feita pelos membros do Núcleo de Pesquisa e Estudos Qualitativos (NUPEQS) da Universidade Estadual de Campinas (UNICAMP). A amostra foi determinada pelo critério de exaustão. Para a análise dos dados empregamos a técnica de Análise de Conteúdo Temática que se desdobrou nas seguintes etapas: pré-análise, exploração do material e, tratamento dos resultados, inferência e a interpretação.

Para a identificação dos diferentes recortes temáticos oriundos das falas das enfermeiras, utilizados na discussão dos resultados, empregamos a letra "E" de entrevista e o número sequencial em que as entrevistas foram realizadas.

\section{RESULTADOS}

Em relação ao sexo, $100 \%$ da amostra é do sexo feminino, fato esperado pela grande predominância de potencial de trabalho feminino na profissão. $O$ grupo etário das participantes da amostra estudada oscilou entre 24 e 43 anos. A enfermeira com menor tempo de atuação nos serviços de saúde da família encontra-se inserida nos serviços há três meses e a com maior tempo está há 15 anos.

Sobre a participação em algum curso de formação específica em saúde mental, 16 (84,2\%) enfermeiras referiram terem participado de um curso de 40 horas oferecido pela Secretaria Municipal de Saúde, cujo objetivo foi sensibilizar os trabalhadores da equipe de saúde da família acerca da saúde mental no contexto dos serviços da Estratégia Saúde da Família.Apenas 3 (I5,8\%) enfermeiras participantes da pesquisa não participaram do referido curso.

A partir da análise das falas das entrevistadas por meio das etapas que compõe o processo de Análise de Conteúdo Temática, realizamos a pré-análise (respeitando as normas de validade em pesquisa qualitativa), a exploração do material, com a finalidade de se identificar os núcleos de sentido que foram essenciais à construção das categorias temáticas depreendidas: ferramentas utilizadas para o desenvolvimento do cuidado em saúde mental (encaminhamento do usuário com transtorno mental; tratamento medicamentoso e acolhimento, vínculo e escuta) e limitações para a efetivação do cuidado em saúde mental (desconhecimento/fragilidades nos processos formativos em saúde mental; saúde mental: uma questão de afinidade e o imperativo do medo) e por fim a interpretação dos dados obtidos.

\section{DISCUSSÃO}

Categoria Temática I. Ferramentas utilizadas para o desenvolvimento do cuidado em saúde mental
Após a leitura das falas das enfermeiras percebemos que estas utilizaram diferentes elementos que consideram relevantes à produção do cuidado em saúde mental na atenção básica, sendo estes: processo de encaminhamento do usuário com transtorno mental e o tratamento medicamentoso como forma de cuidado e; o vínculo, acolhimento e a escuta.

O encaminhamento da pessoa com transtorno mental é representado por algumas enfermeiras como forma de cuidado, este encaminhamento pode associar-se a uma dificuldade por parte da profissional em atender a uma necessidade específica em saúde mental, bem como, uma forma de ofertar a este usuário serviços especializados requeridos em algumas circunstâncias.

Seria uma coisa muito de encaminhar [o usuário com transtorno mental] [...] (EI).

[...] a gente encaminha [a pessoa com transtorno mental] para o próprio psicólogo do NASF [...] (E3).

[...] é mais essa questão de identificação [do portador de transtorno mental] e encaminhamento [...] (EI9).

Por outro lado, esta situação pode relacionar-se com a percepção que as participantes do estudo têm sobre o processo saúde-doença, em que a lógica da especialização do atendimento ganha maior visibilidade. A prescrição de medicamentos e a sua administração são representados como forma de produção de cuidado em saúde mental. Tal prática associa-se a um conceito cujo cerne limita-se à doença e cura. $\mathrm{O}$ emprego da medicalização entendido como gerador do cuidado em saúde mental pode ser visto como algo que ameniza os sintomas, entretanto, mascara o sofrimento conduzindo o usuário ao agravamento do quadro ou mesmo à cronicidade ${ }^{(8)}$.

[...] administrei a medicação nele [pessoa com transtorno mental] (E9).

[...] o que ela [médica] faz no máximo, é trocar receita $[\ldots]$ (EI0).

[...] desde quando eu me formei na verdade a participação da gente era exclusiva em troca de receita [...] (EI2).

[...] a medicação dela [usuária com transtorno mental] está aqui no armário [...] (E|6).

Neste contexto, uma demanda importante relacionada à saúde mental chega diariamente aos serviços da atenção básica, considerados a "porta de entrada" do sistema de saúde, com a expectativa de que o profissional possa dar resposta ao seu sofrimento de modo rápido e eficaz. Entretanto, uma série de circunstâncias dificultam o acolhimento e o tratamento dos usuários. A falta de diretrizes do Ministério da Saúde, a falta de preparo técnico do profissional, as precárias condições de trabalho, a falta de investimento pelos gestores dentre outras, fazem com que a demanda em saúde mental seja tratada apenas 
com medicação, produzindo-se assim uma medicalização do sofrimento(9).

O encaminhamento e a ênfase dada à medicalização como elementos que objetivam os instrumentos/possibilidades para a produção do cuidado em saúde mental convergem para uma atenção individualizada, passiva e indicativa de baixa resolutividade. Nos recortes das falas de EIO e EI2 a representação sobre a possibilidade de cuidado em saúde mental pauta-se no uso de medicamentos, e se ancora no que o outro trabalhador da equipe, o médico, produz. Isto evidencia que a prática cotidiana da enfermeira na Estratégia Saúde da Família, produz e se reproduz a partir do que emerge no seu universo consensual.

Outros elementos que emergiram da fala de algumas entrevistadas foram: o acolhimento, o vínculo e a escuta como dispositivos essenciais ao desenvolvimento do cuidado em saúde mental. Estes constituem um tripé de grande importância na produção do cuidado em saúde mental e estão intimamente relacionados. Desse modo, há uma aposta no acolhimento, estabelecimento de vínculos e incentivo à responsabilização compartilhada dos casos como recurso para evitar a lógica do encaminhamento(9).

No recorte de $E 3$, a seguir, embora exista um reconhecimento do acolhimento como possibilidade para a produção do cuidado em saúde mental, esta não o toma na sua essência e afirma que a instituição de ações programáticas é que configura o desenvolvimento do cuidado em saúde mental. A situação apresentada mostra como a materialidade acerca das ações ganha espaço na prática profissional e a subjetividade se torna algo secundário.

[...] a gente procura acolher e escutar [pessoa com transtorno mental], mas, não existe uma ação específica programática [...] (E3).

[...] a gente procura ter um melhor acolhimento, acoIher [o usuário com transtorno mental] [...] (E9).

[...] ela [pessoa com transtorno mental] precisa de um acompanhamento e acho que o acolhimento até isso existe você acolher, você receber, você encaminhar (EI3).

Desta maneira, o acolhimento desenvolvido nas Unidades de Saúde da Família constitui-se num dispositivo para a formação de vínculo e a produção do cuidado entre trabalhador e usuário. Estes encontros com os usuários possibilitam à enfermeira identificar demandas de saúde em seu território. Isto implica na construção de recursos coletivos e individuais de cuidado ${ }^{(10)}$.

O vínculo, como elemento relevante na produção do cuidado em saúde mental amplia a eficácia das ações de saúde e contribui para que o usuário seja coparticipante neste processo. Este instrumento deve ser entendido como espaço de construção de sujeitos autônomos (trabalhador-usuário), visto que, não há construção de vínculo sem que o usuário seja reconhecido na qualidade se sujeito que fala, julga e deseja ${ }^{(11)}$.

Segundo os fundamentos e diretrizes, impressas na Política Nacional da Atenção Básica, o vínculo consiste na construção de relações de afetividade e confiança entre o usuário e o trabalhador da saúde, o que possibilita aprofundar o processo de corresponsabilização pela saúde, construído ao longo do tempo, além de carregar, em si, um potencial terapêutico ${ }^{(12)}$.

[...] esses pacientes [usuários com transtornos mentais] são desconfiados né? Até criar um vínculo com o novo profissional leva um tempo [...] (E2).

[...] dentro dessa lógica da saúde da família é o vínculo estreito que você tem com a comunidade [...] (E5).

[...] encaminhei [usuária com transtorno mental] para o CAPSi, e ai ela retorna pra conversar, ela inclusive mudou pra área, mas criou esse vínculo comigo então ela volta pra mim [...] (EI8).

A formação do vínculo se dá pela aproximação entre usuário e trabalhador de saúde, ambos com intenções, interpretações, necessidades, razões e sentimentos. Entretanto, em situação de desequilíbrio, habilidades e expectativas distintas o usuário busca assistência, em seu estado físico e emocional fragilizado junto ao trabalhador de saúde, supostamente capacitado para atender e cuidar da etiologia da sua fragilidade ${ }^{(13)}$.

A escuta emergiu como outra possibilidade/instrumento para o desenvolvimento do cuidado em saúde mental. Nesta vertente, algumas habilidades interpessoais carecem ser desenvolvidas, dentre as quais, a escuta é entendida como um instrumento indispensável à relação de ajuda ${ }^{(8)}$.

[...] Quando a boca cala o corpo fala não é isso? [...] Quando se promove um grupo que você permite que as pessoas falem também você está promovendo saúde mental [...] (EI).

El reconhece que o não compartilhamento do usuário sobre suas necessidades e angústias contribui para a manifestação do adoecimento físico. Destarte, a incapacidade de se expressar ou transmitir emoções e sentimentos - inclusive de agressividade - resulta em importante mecanismo de agressão ao corpo e, por consequência, em causa de doenças ${ }^{(14)}$.

[...] ela [usuário com transtorno mental] precisa, talvez, falar, ser ouvida para ter troca [...] (E3).

[...] quando a gente escuta alguém, na consulta de planejamento familiar, que a mulher desabafa por algum problema, então eu acho que ali eu estou cuidando da saúde mental dela. [...] (E5).

No escutar, colocamo-nos no espaço objetivo externo e subjetivo interno do outro, por meio de uma participação, de um compartilhar do vivido, diferentemente de ouvir que se caracteriza apenas pela constatação de 
algo por meio do sistema auditivo, isto é, uma ação fisiológica que demanda uma constituição neurológica ${ }^{(15)}$.

Portanto, o serviço de saúde deve se organizar para assumir a sua função central de acolher, escutar e oferecer uma resposta positiva, capaz de resolver a maioria dos problemas de saúde da população ou minimizar danos e sofrimentos desta. A proximidade e a capacidade de acolhimento, vinculação, responsabilização e resolutividade são essenciais para a efetivação da atenção básica como contato e "porta de entrada" preferencial da rede de atenção à saúde ${ }^{(12)}$.

Uma das enfermeiras entrevistadas usa o termo escuta qualificada para designar a relação estabelecida entre trabalhador e usuário com a finalidade de identificar as necessidades na perspectiva do usuário. Esta escuta refere-se a uma abordagem centrada no usuário e envolve uma escuta atenta. A escuta qualificada passa a ser representada como uma possibilidade para efetivação do cuidado em saúde mental na Estratégia Saúde da Família pela enfermeira.

[...] Eu acho que uma ação que está atrelada ao cuidado em saúde mental na saúde da família é a escuta qualificada desse paciente [pessoa com transtorno mental] pra você saber o que ele vai aceitando, o que ele vai buscando [...] (EI8).

Mesmo a escuta sendo identificada como elemento inerente à produção do cuidado em saúde mental na Estratégia Saúde da Família, uma enfermeira afirma que a forma como o processo de trabalho está organizado e considerando o tempo necessário à escuta, são fatores que a impossibilita de operacionalizá-la em seu trabalho. Isto é algo que compromete a assistência direta ao usuário quando se pensa na de integralidade do cuidado.

[...] se a gente tivesse como tirar um dia, tirar uma hora pra essas pessoas [pessoas com transtornos mentais] serem ouvidas [...] (EI7).

Tal situação é preocupante uma vez que a ausência da escuta pode ter para o usuário um significado negativo, ou seja, de que este não merece que os profissionais lhes dediquem tempo ou ainda ser visto como uma falta de interesse do profissional para ele, o que pode levá-lo a construir ou ampliar um sentimento de desvalorização(8).

Ao finalizar a presente categoria que discutiu as ferramentas utilizadas pelas enfermeiras para o desenvolvimento do cuidado em saúde mental, observamos que as participantes do estudo, embora não tenham se apropriado dos instrumentos/possibilidades para a produção de cuidado em saúde mental nos seus processos de trabalho, demonstraram conhecer recursos inerentes a sua gestão.A identificação de elementos que dificultam o desenvolvimento prático deste cuidado contribuirá para novas reflexões no sentido de se (re)pensar mecanismos para que o cuidado em saúde mental seja concretamente efetivado na prática cotidiana da enfermeira, nos cená- rios das equipes de saúde da família. Algumas destas dificuldades são discutidas na próxima categoria temática.

\section{Categoria Temática 2. Limitações para a efetiva- ção do cuidado em saúde mental}

Existe grande dificuldade de implantação do que é preconizado pelas políticas públicas. As práticas de saúde mental na atenção básica estão muito vinculadas ao modelo biomédico, o que colabora para a falta de preparo dos profissionais ${ }^{(16)}$. Sobre a formação em saúde mental, as enfermeiras participantes do estudo retrataram em suas falas uma deficiência em seus processos formativos na graduação e após a sua inserção nos serviços de saúde, situação esta que se associa a invisibilidade que o cuidado em saúde mental na Estratégia Saúde da Família adquire. No fragmento da fala de El o cuidado em saúde mental é percebido como algo complexo e, o despreparo associado à formação faz com que este cuidado não seja incorporado ao processo de trabalho da enfermeira.

[...] tudo que a gente não entende a gente acha complicado e complexo [...] eu mesma não tenho capacitação nenhuma voltada para a saúde mental a não ser essa mesma capacitação de sete dias que a meu ver é muito pouco pra uma coisa tão complexa [...] Eu não me vejo ainda assim, fazendo um acompanhamento, um atendimento com bastante firmeza, destreza em saúde mental não. [...] a minha formação é muito recente [graduou-se em $20 \mathrm{II}$ ], eu considero muito boa, mas, ainda está voltada para o individual, a gente ainda não conseguiu abrir os olhos para o geral e, saúde mental é isso. [...] (EI).

A enfermeira evidencia uma formação recente, no entanto, com elementos presentes em sua fala que retrataram a falta de conhecimento sobre saúde mental. Situação que pode estar atrelada às deficiências no projeto político pedagógico do curso de graduação realizado, ou a forma como o conteúdo sobre saúde mental, como núcleo de competência do profissional enfermeiro foi conduzido.

Nos recortes das falas das enfermeiras deste estudo, há uma ancoragem às deficiências percebidas, especificamente, na disciplina de enfermagem em saúde mental, especialmente, quando estas referem-se a parte prática, cujas habilidades foram desenvolvidas exclusivamente no contexto hospitalar, não sendo este, na atualidade o principal dispositivo de reabilitação psicossocial.

A gente sai da graduação sem saber como trabalhar o indivíduo, saúde mental na unidade de saúde da família [...] (EI6).

[...] eu tive uma formação muito hospitalocêntrica, onde eu estudei era tudo muito hospital [...] (EI7).

Sobre a formação acadêmica dos profissionais de enfermagem, percebe-se que esta continua sendo gerada a 
partir de um currículo organizado por disciplinas específicas com ênfase nas especialidades. Esta falta de integração entre as disciplinas contribui para uma prática docente docentes sem interação e futuros profissionais que reproduzirão uma prática assistencial fragmentada, contribuindo para uma conformação do modelo manicomial ${ }^{(17)}$.

A situação exposta anteriormente é preocupante, uma vez que ao se defrontar com a realidade, o novo profissional pode vivenciar uma contradição paradigmática, pois não está apto a lidar com situações cotidianas em que usuários demandem ações de saúde mental nos serviços de saúde da família. Esta situação gera uma prática de encaminhamento a profissionais especializados sem o mínimo de acolhimento e resolutividade nos cuidados de enfermagem ${ }^{(17)}$. Estabelecer o diálogo entre saúde mental e atenção básica, nos cursos de graduação em enfermagem pode ser um importante instrumento para mudar a situação que ora se apresenta.

Ademais, algumas enfermeiras por meio de suas falas evidenciaram que a formação pautada na educação permanente em saúde emerge como algo paradoxal, ou seja, ao mesmo tempo em que E8 sinaliza como fator limitador a falta de motivação e interesse do trabalhador com a temática, distintamente, E2 e EI 0 relatam que a formação recebida por parte da Secretaria Municipal de Saúde não foi suficiente para a operacionalização concreta e efetiva do cuidado em saúde mental, especificamente, aos usuários com transtornos mentais.

[...] eu diria que não me sinto apta, porque assim, por mais que a gente teve essa capacitação de quarenta horas [...] eu não me sinto $100 \%$ segura de atender um paciente com transtorno mental [...] (E2).

$O$ que dificulta é só a gente ter a vontade de fazer, porque a gente tem o espaço, a gente já foi capacitada tanto o enfermeiro, a equipe inteira foi capacitada em saúde mental. [...] saúde mental não sei, a gente não tem assim, aquele estímulo da própria equipe [...] (E8).

[...] Depois da capacitação [em saúde mental], pra mim foi à mesma coisa [...] $O$ contato que a gente tem aqui é muito pouco, com os pacientes de saúde mental. [...] $O$ despreparo para lidar com essas pessoas [...] (EI0).

A partir das falas anteriores, percebemos que a educação deve ser compreendida como um processo permanente que nasce durante a graduação e que deve ser mantida durante a vida profissional. A formação por meio da atualização técnico-científica é apenas um dos aspectos da qualificação das práticas e não o seu cerne. Isto faz com que a formação envolva outros elementos como a produção de subjetividade, produção de habilidades técnicas e de pensamento e o adequado conhecimento do SUS ${ }^{(18)}$.
Outro elemento presente nos fragmentos das falas de algumas enfermeiras refere-se à falta de afinidade em lidar com os usuários com transtornos mentais, como evidenciados nos recortes seguintes de E3 e E9. A falta de afinidade pode ser justificada por outro elemento no qual as enfermeiras ancoraram suas limitações para a produção do cuidado em saúde mental: o medo em lidar com o usuário com transtorno mental, que será discutido a posteriori.

É [...] capacitar né? [risos] sensibilizar, porque assim, por mais que a gente receba capacitação, mas se é uma área que eu não tenho muita afinidade eu vou sempre ter bloqueio [...] (E3).

[...] eu não tenho manejo com pacientes de saúde mental [...] a gente tem que ser mais sensível quando se trata de um paciente desse, não é? E aí eu tenho o medo de perder o equilibrio na hora, de não ter aquela sensibilidade que o paciente precisa, entendeu? [...] desde a época da faculdade eu nunca quis trabalhar com pacientes de saúde mental [...] (E9).

Neste caso, o sentimento de medo emanado do universo consensual se sobrepõe ao que é próprio do universo reificado, ou seja, o (des)conhecimento que as participantes da pesquisa têm com relação ao cuidado em saúde mental, uma vez que percebemos que as enfermeiras ancoraram seus significados no transtorno mental, entendido como doença para representar o cuidado em saúde mental.

Outro aspecto atrelado à formação das enfermeiras, presente na fala de uma participante da pesquisa referese à falta de cobrança por parte da gestão dos serviços de saúde, acerca das ações produzidas por esta no campo da saúde mental. Esta situação corrobora para que a incorporação da produção do cuidado em saúde mental não se concretize na prática cotidiana da enfermeira.

[...] todos os profissionais foram capacitados [...] Foi um curso grande, todos passaram por uma semana de capacitação, aprendemos bastante [...].Toda a equipe foi capacitada, mas, assim, a gente ainda não conseguiu descobrir como colocar isso em prática [...] falta de política pública mesmo, de cobrar dados, de cobrar resultados em relação ao que falei de saúde mental. [...] (E4).

O fragmento anterior reforça o quanto a enfermeira está acostumada com um modelo de produção capitalista, cuja lógica de produtividade em saúde, especialmente, a cobrança do que se produz, ancora a representação social da mesma.

O sentimento de medo em relação ao usuário com transtorno mental foi identificado e retrata as representações sociais que algumas enfermeiras têm acerca das limitações para a produção do cuidado em saúde mental. De forma expressiva, esta situação pôde ser constatada nos fragmentos das falas seguintes. 
[...] vem um paciente com transtorno mental grave $\mathrm{e}$ se ele entrar em surto aqui na unidade? Entendeu? Aí a gente fica meio limitada com isso, meio receosa [...] (E2).

[...] eu cheguei a casa [da pessoa com transtorno mental] super assustada [...] é esse receio que a equipe fica $[. .$.$] (EI2).$

[...] o medo do profissional em lidar com certos transtornos [...] a gente não tem preparação pra estar lidando com aquele transtorno naquele momento; aquele surto. [...] (EI5).

[...] a grande maioria dos profissionais tem até certo receio de se trabalhar com o doente de saúde mental, acho que é por medo. [...] tem profissionais que tem medo da agressão [...] (EI6).

Grande parte das enfermeiras participantes do estudo, ao representar as limitações para a produção do cuidado em saúde mental trouxe em suas falas elementos que se ancoraram no medo em lidar com pessoas com transtornos mentais. Esta situação contribuiu e continua contribuindo para a exclusão social que ocorre no território e dentro do próprio espaço físico da unidade de saúde.

O imaginário social do "louco" e da "loucura" emergiu nas falas das enfermeiras, uma vez que, como sujeito da história, estas assimilaram os conceitos recebidos do convívio social, por meio de seus universos consensuais, espaço este, onde naturalmente suas representações sociais são produzidas. Nesta vertente, Foucault ${ }^{(19)}$ em sua obra a "História da loucura" aponta que a estigmatização do "louco" prevaleceu ao longo do tempo o que consequentemente possibilitou a exclusão social dessas pessoas.

Portanto, as representações sociais da "loucura" ainda são marcadas por estigmas e preconceitos, a partir dos conceitos cristalizados nas falas das enfermeiras. Esse sentimento de medo impregnado de estereótipos associa-se ao aspecto agressividade atribuída ao usuário com transtorno mental, principalmente, em situações de crise.

Periculosidade, agressividade e medo fazem parte de um mesmo processo de construção histórica no qual se manifesta um circulo vicioso em que a noção de periculosidade potencializa a percepção de agressividade, aumenta o estigma da exclusão e alimenta o medo dos trabalhadores de saúde ${ }^{(20)}$. Desse modo, olhar a agressividade apenas como uma manifestação destrutiva e insalubre contribui para a prática de intervenções direcionadas ao ajuste e o enquadramento do sujeito. É necessário que as enfermeiras percebam, nessas manifestações de agressividade em crise, mais esperança do que desespero, mais carência do que maldade, mais apelo do que destrutividade e passem a intervir com o sujeito e para o sujeito ${ }^{(20)}$.

Diante do que foi discutido nesta categoria percebemos que o trabalho das enfermeiras na Estratégia Saúde da Família desta amostra, esbarra em distintas limitações que direta ou indiretamente contribuem para a forma como o cuidado em saúde mental é representado. Com o que foi apresentado nota-se que a produção do cuidado em saúde mental tem sido relegada a partir de carências das próprias enfermeiras, dos serviços de saúde e das instituições formadoras.

\section{CONCLUSÃO}

O cuidado em saúde mental para as enfermeiras da Estratégia Saúde da Família ganhou representatividade a partir da anormalidade, ou seja, do processo de "adoecimento" mental dos usuários, com isso as representações sociais das participantes do estudo foram cristalizadas a partir da figura do usuário com transtorno mental. $O$ usuário com transtorno mental foi referência para que as participantes da pesquisa representassem as possibilidades e limitações para a produção do cuidado em saúde mental na Estratégia Saúde da Família.

Como possibilidade para a produção do cuidado em saúde mental nos serviços de saúde da família, as enfermeiras de nossa amostra ancoraram suas percepções em elementos que representaram o encaminhamento do usuário com transtorno mental a serviços especializados da rede de atenção psicossocial; a apropriação do acolhimento, vínculo e da escuta como elementos inerentes ao cuidado em saúde mental.

As representações sociais sobre as limitações para a produção do cuidado em saúde mental na saúde da família, segundo as participantes do estudo, estiveram associadas às deficiências em seus processos formativos durante a graduação e em suas trajetórias como profissionais, o que evidencia um desafio a ser superado por parte das instituições formadoras, bem como para a gestão dos serviços municipais de saúde no sentido de qualificar os profissionais para que o cuidado em saúde mental na atenção básica seja entendido como indissociável da produção de cuidado como um todo.

A busca por estratégias que descontruam estereótipos de medo associado ao usuário com transtorno mental se faz necessária para a concretização da atenção psicossocial no contexto proposto pela Reforma Psiquiátrica Brasileira no cenário da Estratégia Saúde da Família.

Portanto, embora as equipes de atenção básica, especialmente, de saúde da família sejam consideradas importantes dispositivos de atenção psicossocial, as representações sociais das enfermeiras que atuam neste cenário desvelaram que se faz necessário descontruir crenças e valores acerca do "louco" e da "loucura", bem como, investir em qualificação profissional para que os serviços de saúde da família possam ser considerados a principal "porta de entrada" para os usuários do SUS, inclusive àqueles com algum grau de sofrimento psíquico ou transtorno mental. 


\section{REFERÊNCIAS}

I. Tanaka OU, Ribeiro EL. Ações de saúde mental na atenção básica: caminho para ampliação da integralidade da atenção. Ciênc. Saúde Coletiva [Internet]. 2009 [acesso em 15 de março de 20/3]; 14(2): 477-86. Disponível em: http://www. scielo.br/pdf/csc/v14n2/a I6v|4n2.pdf.

2. Ministério da Saúde (BR). Secretaria de Atenção à Saúde. DAPE. Coordenação Geral de Saúde Mental. Reforma psiquiátrica e política de saúde mental no Brasil. Documento apresentado à Conferência Regional de Reforma dos Serviços de Saúde Mental: 15 anos depois de Caracas [Internet]. OPAS [Acesso em 05 de novembro de 2013]. Brasília: Ministério da Saúde; 2005. 5 I p. Disponível em: http://bvsms.saude.gov.br/bvs/publicacoes/Relatoriol5 anos_Caracas.pdf.

3. Russell G, Potter L. Mental health issues in primary healthcare.J. Clin. Nurs [Internet]. 2002 [cited 2013 June 04]; I I: I I8- 125. Available from: http://onlinelibrary.wiley.com/doi//0.1046/ j. 13652702.2002.00588.x/epdf.

4. Nolan E, Hewison A. Teamwork in primary care mental health: a policy analysis. J. Nurs. Manag [Internet]. 2008 [ cited 2013 June 16]; |6:649-6I. Available from: http://onlinelibrary.wiley. com/doi/l 0. I I I I/j. I 3652934.2007.00766.x/epdf.

5. Sá CP. Representações sociais: o conceito e $O$ estado atual da teoria. In:Spink MJP (Org.). O conhecimento no cotidiano: as representações sociais na perspectiva da psicologia social. São Paulo: Brasiliense; 2004. p. 1 9-45.

6. Moscovici S. Representações sociais: investigações em psicologia social. Petrópolis:Vozes; 2010.

7. Yin RK. Estudo de Caso: planejamento e métodos. Porto Alegre: Bookman; 2010.

8. Souza RC, Pereira MA, Kantorski LP. Escuta terapêutica: instrumento essencial do cuidado em enfermagem. Rev. Enferm. UER] [Internet]. 2003 [acesso em 29 de abril de 20 I3]; II: 92-7. Disponível em: http://www.facenf.uerj.br/vl|nl/ vllnlal5.pdf.

9. Onocko-Campos R, Gama C. Saúde mental na atenção básica. In: Campos, GWS, Guerrero AVP. (Orgs.) Manual de práticas de atenção básica: saúde ampliada e compartilhada. São Paulo: Hucitec; 2010. p. 22I-46.

10. Ministério da Saúde (BR). Secretaria de Atenção à Saúde. Departamento de Atenção Básica. Saúde mental / Ministério da Saúde, Secretaria de Atenção à Saúde, Departamento de Atenção Básica, Departamento de Ações Programáticas Estratégicas. Brasília: Ministério da Saúde; 2013.

II. Schimith MD, Lima MADS. Acolhimento e vínculo em uma equipe do programa saúde da família. Cad. Saúde Pública [Internet]. 2004 [acesso em 04 de maio de 2014]; 20(6): 1487-94. Disponível em: http://www.scielo.br/pdf/csp/ v20n6/05.pdf.

12. Ministério da Saúde (BR). Secretaria de Atenção à Saúde. Departamento de Atenção Básica. Política Nacional de Atenção Básica / Ministério da Saúde. Secretaria de Atenção à Saúde. Departamento de Atenção Básica. Brasília: Ministério da Saúde, 2012. 110 p.

13. Monteiro MM, Figueiredo VP, Machado MFAZ. Formação do vínculo na implantação do programa saúde da família numa unidade básica de saúde. Rev. Esc. Enferm. USP [Internet]. 2009 [acesso em 09 de agosto de 2013]; 43(2): 35864. Disponível em: http://www.scielo.br/pdf/reeusp/v43n2/ al $5 v 43 n 2 . p d f$.

14. Silva MAD. Quem ama não adoece. São Paulo: Best seller; 2004. 15. Hirdes A. Centro de saúde mental de São Lourenço do Sul: resgatando possibilidades de reabilitação psicossocial [Dissertação]. Florianópolis (SC): Universidade Federal de Santa Catarina [Internet]; 2000. [acesso em 18 de setembro de 2013]. Disponível em: https://repositorio.ufsc.br/ bitstream/handle/I23456789/78738//73 I88.pdf?sequen$\mathrm{ce}=\mid$ \&isAllowed $=\mathbf{y}$.

16. Pires D.A enfermagem enquanto disciplina, profissão e trabalho. Rev. Bras. Enferm. [Internet].2009 [acesso em 02 de abril de 2013]; 62(5): 739-44. Disponível em: http://www. scielo.br/pdf/reben/v62n5//5.pdf.

17. Rodrigues J, Santos SMA, Spriccigo JS. Teaching nursing care in mental health in undergraduate nursing. Acta Paul. Enferm [Internet]. 2012 [cited 2014 August 05]; 25(6): 844-5I. Available from: http://www.scielo.br/pdf/ape/v25n6/en_ v25n6a04.pdf.

18. Ceccim RB, Feuerwerker LCM. O quadrilátero para a formação para a área da saúde: ensino, gestão, atenção e controle social. Physis [Internet]. 2004 [Acesso em 28 de março de 20I4]; I4(I): 4I-65. Disponível em: http://www. scielo.br/pdf/physis/vl4nl/vl4n la04.pdf.

19. Foucault M. A história da loucura. São Paulo: Perspectiva; 1972.

20. Bonfada D, Guimarães J, Brito AAC. Concepções de profissionais de saúde de atendimento móvel quanto à urgência psiquiátrica. Rev. Rene [Internet]. 2012 [acesso em 10 de maio de 2014]; 13(2): 309-20. Disponível em: http:// www.revistarene.ufc.br/revista/index.php/revista/article/ view/2/4/pdf. 